\title{
Motivation, Satisfaction, and Retention of Sport Management Student Volunteers
}

\author{
James E. Johnson ${ }^{1}$ \\ Chrysostomos Giannoulakis ${ }^{1}$ \\ Nathan Felver ${ }^{1}$ \\ Lawrence W. Judge ${ }^{1}$ \\ Pierce A. David ${ }^{2}$ \\ Beau F. Scott ${ }^{1}$
}

\begin{abstract}
Sport management programs often partner with intercollegiate athletic depart-ments or community sport organizations to provide student volunteers. Motivat-ing, satisfying, and retaining the student population may constitute a challenge for academic program stakeholders. The purpose of this study was to examine the relationship between motivation, satisfaction, and retention of volunteers at undergraduate sport management programs. Three hundred and twenty-two undergraduate students from five Midwestern institutions completed a 46-item questionnaire assessing their volunteer motivation, satisfaction, and retention. Results indicated students were predominantly motivated to volunteer by Love of Sport and Career motivation factors. Career, Social, Understanding, and Enhancement motivations significantly aided in predicting satisfaction, while Career, Social, and satisfaction significantly predicted retention. Implications for sport management academic programs and directions for future research are discussed.
\end{abstract}

Keywords: Sport volunteerism, sport management students, motivation, satisfaction, retention

1. Ball State University.

2. Department of Tourism, Conventions, and Event Management at Indiana University Purdue University Indianapolis.

Please send correspondence to James Johnson, jejohnson1@bsu.edu

This is the author's manuscript of the article published in final edited form as: Johnson, J. E., Giannoulakis, C., Felver, N., Judge, L. W., David, P. A., \& Scott, B. F. (2017). Motivation, Satisfaction, and Retention of Sport Management Student Volunteers. Journal of Applied Sport Management; Urbana, 9(1). 
Literature has widely acknowledged volunteerism as an essential part of sport and recreation service delivery because a large number of individuals are often necessary for creating and delivering these services (e.g., Bang \& Ross, 2009; Chelladurai, 2014; Farrell, Johnston, \& Twynam 1998; Strigas \& Jackson, 2003). Chelladurai (2014) appraised the economic value of sport volunteers at more than $\$ 50$ billion worldwide. This estimate indicates $20 \%$ of the financial value within the $\$ 260$ billion volunteer industry was in sport and recreation. Volunteer opportuni-ties are increasingly available through the curriculums of major and general uni-versity education courses, especially in sport management/administration-related settings (Pierce, Johnson, Felver, \& Wanless, 2014). Studies that have examined youth and college student volunteers have rarely focused on sport management or recreation programs (Burns, Reid, Toncar, Fawcett, \& Anderson, 2006). These general studies on university students, while important to the volunteerism body of literature, do not isolate students that have aspirations for a career in sport, and are most likely to engage in sport-related volunteer opportunities.

Studying sport management student volunteerism is warranted due to the in-terconnectedness between volunteerism and sport. As other academic disciplines have unique curriculums and volunteer contexts, so does sport. In fact, sport is a discipline so reliant on volunteerism that it is an expected and essential part of students' education (Pierce, Wanless, \& Johnson, 2014). When one considers that $20 \%$ of the global volunteer market is devoted to sport (Chelladuri, 2014), it becomes clear how important a role future sport managers play throughout the volunteer industry. Furthermore, with 613 sport management programs in the United States (U.S.) alone (Pedersen \& Thibault, 2014) and more than 8,000 grad-uates annually, the impact of this potential volunteer workforce on local, regional, state, and national sporting events is evident (Jones, Brooks, \& Mak, 2008; Math-ner \& Martin, 2012).

Beyond the educational expectations in sport management programs (Pierce et al., 2014) and the immense financial reliance on sport volunteers (Chelladurai, 2014), sport is an inimitable context because it is often an event-based form of entertainment. This context may be vastly different from volunteer contexts in traditional academic disciplines, because it provides a wealth of applied, hands-on experiences often surrounded by events occurring at a specific place and time (Pierce, Johnson et al., 2014). Thus, the sport volunteer experience is often defined by duties in relationship to an event. In such an environment volunteers may be prone to a plethora of motivations for volunteerism. An interest in a particular sport, type of event, volunteer duty, social opportunity, or a general love for sports (Bang \& Ross, 2009) may inspire a particular volunteer. For sport management students, it is also reasonable to believe professional development plays a role in volunteer behavior (Pierce, Johnson et al., 2014).

To capitalize on professional development, sport management programs often partner with their institution's athletic departments or community sport organizations to provide volunteer experiences for their students. For instance, academic departments formulate professional student organizations (PSOs) "in an effort to 
promote professional development, increase networking opportunities, provide opportunities for application, analysis, synthesis, and evaluation, and integrate students into the institution" (Bodey, 2008, p. 8). This reciprocal partnership between sport management programs and institutional/community sport organizations is often beneficial for students, programs, and the organizations with whom they volunteer. Ideally, students gain practical experiences and the athletic depart-ments or community organizations secure a cost-effective and specialized pool of eager volunteers.

Despite evident advantages, motivating college students to volunteer can be challenging due to volunteer opportunities competing with family, friends, jobs, and other activities for a share of students' attention (Astin, 1984; Bodey, 2008). Nonetheless, sport management students possess unique qualities that may position them well as volunteers. For example, university students are thought to have high levels of creativity and innovation, as well as enough flexibility in their academic schedules to serve as volunteers (Burns et al., 2006; Foster \& Dollar, 2010). Furthermore, university students tend to view their volunteer work as a learning experience or as a stepping-stone to an occupation, whereas nonstudents may perform voluntary tasks because of normative or social pressures (Vianen, Nijstad, \& Voskuijl, 2008). In particular, sport management students appear to have enhanced incentives for sport volunteerism due to the practical nature of event management, which is often a central component of sport management cur-ricula (Pierce, Johnson et al., 2014). Increased volunteerism in the college student demographic has been supported by Burns et al. (2006), who found college stu-dents volunteer at nearly double the amount of other types of volunteers. In turn, volunteer activities enhance learning and personal development through a height-ened level of overall involvement (Astin, 1984).

Since volunteerism is thought to benefit students in terms of practical experience, immersive learning, and personal development, determining what moti-vates sport management students to volunteer is critical (Foster \& Dollar, 2010). Understanding motivation could lead to a satisfying volunteer experience for students, which could then lead to continued and sustained volunteerism in a large and important volunteer sector (Pierce, Johnson et al., 2014). Although academic research has extensively investigated varying characteristics of volunteers in an assortment of settings (e.g., mega-sporting events, special events, nonprofit events, community events, etc.), volunteerism in sport management higher education programs has largely been ignored (Foster \& Dollar, 2010; Pierce, Johnson et al., 2014). Given the potential impact of this volunteer force within sport, empirical investigation of what motivates, satisfies, and retains sport management student volunteers is warranted. The need for such an investigation is apparent due to the increase of undergraduate and graduate programs worldwide and a subsequent 
surge in student enrollment in the nascent academic field of sport management (Newman, 2014). Furthermore, the analysis of motivation, satisfaction, and reten-tion has rarely been examined in tandem, and this paper provides a way to help faculty and volunteer organizers understand volunteer behaviors (from initial motivation to retention), and ultimately assist in the programming necessary to recruit, satisfy, and retain students. Therefore, the purpose of the current study was to expand on Pierce, Johnson et al.'s (2014) work to examine the interrela-tionship of motivation, satisfaction, and retention within an undergraduate sport management volunteer sample.

\section{Theoretical Perspectives on Sport Volunteerism}

The pivotal role of sport volunteers as social capital for the viability of the sport system has been acknowledged and studied by a plethora of academic re-searchers during the past decade (Bang \& Ross, 2009; Harman \& Doherty, 2014; Kim, Trail, Lim, \& Kim, 2009; Peachey, Bruening, Lyras, Cohen, \& Cunningham, 2015; Reeser, Berg, Rhea, \& Willick, 2005; Strigas \& Jackson, 2003). The nature of these studies varies, with some emphasis on event volunteerism (e.g., Kim et al., 2009), and others are executive or coaching volunteer roles (e.g., Harman \& Doherty, 2014). Whatever the nature of the context, volunteers are an important element to various sporting endeavors because they provide sport managers with the ability to offer and sustain events, as well as expand the quantity, quality, and diversity of a sport organization's services (Strigas \& Jackson, 2003). It is reason-able to infer sport management students could constitute a knowledgeable and motivated volunteer cluster within the greater sport context. To more effectively recruit, manage, and retain sport management student volunteers, an understand-ing of their psychometric characteristics is fundamental in relation to an academic program's organizational context.

\section{Motivation}

From early psychological studies of classical conditioning (Pavlov, 1928) to modern managerial and human resource theories (Chelladurai, 2014), motivation is the foundation from which complex behaviors are understood. Sport volunteer motivation is critical to the identification of relevant tasks, increased chances of beneficial experiences (i.e., satisfaction), and increased likelihood volunteers will return (i.e., retention; Strigas \& Jackson, 2003). Volunteer motivation studies have routinely taken place at large-scale sporting events (e.g., Aisbett, Randle, \& Kappelides, 2015; Fairley, Kellett, \& Green, 2007; Giannoulakis, Wang, \& Gray, 2008; Reeser et al., 2005), special events (e.g., Farrell et al., 1998; Peachey et al., 2015; Stukas, Snyder, \& Gil, 2016; Wang, 2004), and marathons (e.g., Bang \& Ross, 2009; Han, 2007; Hwang, 2010; Strigas \& Jackson, 2003). Such events offer large populations of volunteers that are easily accessible. However, these contexts are spe-cific and may inhibit generalizations of findings to specific volunteer populations (e.g., sport management students). This point is echoed by Wicker and Hallmann 
(2013), who noted that both individual and organizational factors are critical to volunteer engagement.

Within the multicontextual volunteer settings, the work from Clary et al. (1998) and Clary and Snyder (1999) has guided much of the research on motivation. Specifically, the Volunteer Functions Inventory (VFI) has been regularly used since its inception in 1998. The VFI defines and measures six functions/ factors potentially served by volunteerism: Values (express concern for others through helping those that need assistance), Understanding (gain learning experi-ences while sharing one's knowledge, skills, and abilities), Social (motivated by op-portunities to work with others and enhance social relationships), Career (career-related benefits whereby people who volunteer can prepare for a new career or maintain career-relevant skills), Protective (motivating the volunteer by reducing guilt related to being more fortunate than others), and Enhancement (centers on personal development and obtaining satisfaction related to individual growth and self-esteem). These factors have consistently been reused, reworded, and adapted to fit a variety of motivation studies and scales within research on volunteerism (see Bang \& Ross, 2009; Han, 2007; Pierce, Johnson et al., 2014; Wicker \& Hall-mann, 2013).

Despite extensive research derived from Clary et al. (1998) and Clary and Snyder (1999), research on traditional college-aged (or younger) sport volunteers is scarce. Academic studies outside of sport have indicated that youth volunteers are largely motivated to meet people and expand the range of friendships (i.e., McDougle, Greenspan, \& Handy, 2011; Mirsafian \& Mohamadinejad, 2012). Pre-sumably, the Social factor is most salient for this demographic. However, studies on youth or traditional college-aged volunteers have largely omitted studying vol-unteerism in the context of sport, in particular with sport management students (Foster \& Dollar, 2010; Pierce, Johnson et al., 2014). Underlying differences in psy-chometric characteristics between college students in general and sport manage-ment students may exist due to the distinct nature of the sport industry. Namely, the increased competition among sport management students for job placement, as well as the increasing number of graduates, may influence students' percep-tions towards volunteerism (Jones et al., 2008; Mathner \& Martin, 2012). These students could perceive the activity as a competitive advantage within their career portfolios (Pierce, Johnson et al., 2014). Academic programs need to determine how volunteer opportunities for their students fit with the organizational context of the institution, the curriculum, the geographic location, as well as how they align with the program's mission.

To date, Pierce, Johnson et al. (2014) is the single study that has specifically examined sport management student's volunteer motivation and satisfaction. The authors assessed volunteer motives of 103 undergraduate members of a PSO at a Midwestern university (i.e., sport management club), and determined whether motivation factors from the VFI related to satisfaction. In addition to the VFI fac- 
tors, Pierce, Johnson et al. included Love of Sport as a potential motive based largely on work from Bang and Ross (2009), who suggested volunteers are drawn to sport due to their intense interest or love of sport itself. Pierce, Johnson et al. (2014) found Love of Sport, Career, and Understanding as the three highest rated motiva-tion factors. Career and Understanding motives indicated sport management stu-dents were motivated by an opportunity to enhance one's career, and gain learning experiences while sharing knowledge, skills, and abilities. These secondary factors were somewhat consistent with volunteer motivation of non-sport management students, who perceived volunteer activities as a potential avenue for professional development (Bodey, 2008; Mirsafian \& Mohamadinejad, 2012). Results, however, contradicted findings from McDougle et al. (2011) and Mirsafian and Mohamadinejad (2012), who purported college-aged students volunteer primarily for so-cial reasons. Traditional college students may be motivated by different reasons compared to sport management students, whose motivations are primarily related to their unique love of sport and career aspirations. Using the Pierce, Johnson et al. (2014) work as a foundation, the current study attempted to partially replicate the motivation components via a larger and more robust sample. Specifically, the Pierce, Johnson et al. study used one group of students from the same institution's sport management club. The current study incorporated three times the amount of students from five different institutions located throughout the Midwest. Thus, the first research question $(R Q)$ and corresponding hypotheses were adopted;

RQ 1: What factors motivate sport management students to participate in volunteer activities?

Hypothesis 1: Love of Sport and Career will rate as the highest moti-vation factors.

Hypothesis 2: Protective will rate as the lowest motivation factor.

\section{Satisfaction}

Similar to motivation, satisfaction is a widely studied construct in a variety of disciplines. In fact, Dixon and Warner (2010) noted satisfaction is one of the most prevalent topics in organizational research. Satisfaction is often linked to both motivation and retention (Chelladurai \& Ogasawara, 2003; Currivan, 2000), and is frequently conceptualized as a lynchpin necessary to connect the initial vol-unteer desire with an individual's intention to volunteer again. Prior to investigat-ing the interconnectedness among these concepts for sport management student volunteers, an overview of satisfaction and its potential link to volunteer motiva-tion is warranted.

In sport organizational theory, Herzberg's two-factor theory (1966) has been the staple from which satisfaction literature has developed. Central to Herzberg's theory is the notion that satisfaction and dissatisfaction are distinct constructs. 
Satisfaction is largely driven by internal forces specific to the content of a job (e.g., achievement, enhanced job responsibility, ability to grow professionally), and dissatisfaction is mostly influenced by external forces (e.g., administration practices, salary, status). Clary et al. (1998) suggested "overall satisfaction indicates emotional state and fulfillment gained from serving within the volunteering activity" ( $p$. 1524). The emotional component of Clary and colleagues' definition rein-forces the intrinsic and psychological nature of satisfaction proposed by Herzberg (1966). Additionally, researchers (e.g., Bang \& Ross, 2009; Hoye, 2007; Wicker \& Hallmann, 2013) have supported psychological approaches to volunteerism due to their propensity to capture the "interrelationship between sociological and psy-chological processes" (Wicker \& Hallmann, 2013, p. 119). Using this logic, the psychological contract is a sound theory from which to comprehend satisfaction.

The psychological contract "is a cognitive state that is subjective and interpretative, and refers to the development and maintenance of the relationship between the individual and the organization" (Taylor, Darcy, Hoye, \& Caskelly, 2006, p.126). As Harman and Doherty (2014) summarized, there has been con-siderable support for varying psychological contract typologies and expectations. Both transactional (i.e., expectation of tangible rewards such as money) and re-lational (i.e., socioemotional exchanges) contracts have been validated as inde-pendent constructs that can directly impact satisfaction (Nichols \& Ojala, 2009). Studies have also revealed that context is critical to volunteer satisfaction more so than in a traditional employee's environment (Blackman \& Benson, 2010; Har-man \& Doherty, 2014; Vantilborgh et al., 2012). Unique contexts (e.g., academic programs, volunteer opportunities, sport environments) could influence the con-struct of satisfaction differently. Students attending a large National Collegiate Athletic Association (NCAA) Division I (DI) university may have different volun-teer prospects within their athletic departments than students who attend a small NCAA Division III (DIII) institution. For example, a large televised Football Bowl Subdivision football game with 80,000 people in attendance would involve a great deal more volunteers than a small DIII football game with 3,000 people. Opportu-nities in security, television operations, and ticketing are only a few places where volunteer expectations might differ based on the size and scope of the event. In-deed, anticipation of duties, the excitement of the event, and outcomes of volun-teer experiences are likely to generate different expectations for volunteers in different contexts. If these expectations are not met, the psychological contract may be breached and satisfaction could be in jeopardy (Kim et al., 2009). This point is important because the current study examined a sample of sport management stu-dents from large and small universities, rather than examining the most invested students (e.g., club volunteers) from only one type of institution (Pierce, Johnson et al., 2014). Thus, the current study captures a more representative sample of the average sport management student. 
The link between motivation and satisfaction is also pivotal to understanding volunteerism. Bang and Ross's (2009) work confirmed this point when suggesting the three most important motivation predictors for satisfaction were expression of values, career orientation, and love of sport. They estimated an increase in any of the three motivation factors would result in an increase of the respondents' satisfaction with their volunteering experience. Farrell et al. (1998) found satisfaction is not only related to the fulfillment of expectations, but also to the organization of the event and the facilities, thus supporting the contextual nature of satisfaction. Based on these findings, volunteer providers should design specific and unique tasks to each individual volunteer and help fulfill expectations based on motivations (Farrell et al., 1998; Millette \& Gagne, 2008). This matching of task to motivation could provide synergy between volunteers and the organization if expectations are fulfilled. The level of consistency between the expectations held prior to the volunteer activity and the actual volunteering experience is likely to influence overall volunteer satisfaction (Hwang, 2010). This line of reasoning is particularly relevant to sport management programs, as they frequently rely upon volunteer opportunities and community partnerships that benefit their students.

Pierce, Johnson et al. (2014) examined volunteer satisfaction of undergradu-ate sport management students. The authors adopted Clary et al.'s (1998) approach whereby the level of agreement on five statements was used to gauge the level of volunteer satisfaction (e.g., the experience of volunteering with the Sport Management Club [i.e., a student PSO] was a positive one). Results revealed Career, Social, and Love of Sport motivation factors emerged as predictors of satisfaction. Namely, an increase in these three motivation factors resulted in higher levels of satisfaction. These results suggest a link between motivation and satisfaction, and support the notion that sport management students will be satisfied with their experience as long as the experience fulfills expectations (Cnaan \& Goldberg-Glen, 1991). Similar to motivation, the current study expanded the investigation on satisfaction initially used by Pierce, Johnson et al. (2014). Thus, RQ2 and the corresponding hypothesis were developed based on the work by Clary et al. (1998) and Pierce, Johnson et al. (2014).

RQ2: Do certain motivation factors predict satisfaction?

Hypothesis 3: Career, Social, and Love of Sport will predict satisfaction.

\section{Retention}

The intention to continue volunteering, generally regarded as volunteer retention, constitutes a challenge for sport organizations that utilize a volunteer workforce (Chelladurai \& Ogasawara, 2003; Currivan, 2000; Kim, Chelladurai, \& Trail, 2007). Time and resources necessary to recruit and train new volunteers, instead of retaining satisfied volunteers, decreases the efficiency of an organization (Kim et al., 2009). Retention is often used as the dependent variable in volunteer 
research because stakeholders value this construct from a pragmatic standpoint (Kim et al., 2007). Literature indicates motivation, satisfaction, and retention ap-pear to be interconnected, but are rarely investigated in tandem (Fairley et al., 2007; Kim et al., 2007; Kim et al., 2009).

Beyond the logical and anecdotal support often assumed when connecting motivation and satisfaction to retention, researchers have illustrated some em-pirical support linking these concepts (e.g., Cuskelly, Hoye, \& Auld, 2006; Kim et al., 2009). In the sport setting, specifically, there is reason to support the mo-tivation-satisfaction-retention connection. For instance, factors such as off-court administrative and supportive issues, low social interaction, and lack of a referee community contribute to attrition for referees (Warner, Tingle, \& Kellet, 2013). Consequently, social motives are critical to retention of those working in and around sport.

Kim et al. (2007) studied retention of volunteers with the American Youth Soccer Organization (AYSO). The authors examined three aspects of volunteering that potentially affect retention: person-task fit, person-organization fit, and man-agerial treatment. Results indicated the three aspects of volunteering influenced empowerment; however, only $14 \%$ of the variance in retention was explained. The researchers purported further research on sport volunteer retention was neces-sary. As an extension of the aforementioned study, Kim et al. (2009) tested three models to explain intention to continue volunteering (i.e., retention) for Special Olympics volunteers. One model hypothesized the potential moderating effects of the psychological contract on the relationship between fit and empowerment. In past research, fit had been shown to be less important than individual motives for retention (Vianen et al., 2008), suggesting there could be a moderating effect. These findings indicate a volunteer does not have to agree with the goals of an or-ganization (i.e., does not have to be a good fit) or have the skills necessary for the volunteer activity, but can be empowered if expectations are fulfilled. When sport management volunteers work at a sport they do not embrace (i.e., weak personal fit), they can still be satisfied with their experience if they manage to improve their skills. Eventually, their satisfaction could directly influence retention. This connection between satisfaction and retention is a primary contribution of the current study.

Despite the fact that volunteer literature offers insight into sport volunteer retention, specific knowledge about which factors empirically predict retention is restricted. More expressly, retention has not been studied within sport manage-ment student volunteer populations. Although the Pierce, Johnson et al. (2014) study examined motivation and satisfaction, it did not incorporate the retention construct. As service and volunteer opportunities are integral components of aca-demic programs and community sport organizations, the field of sport manage-ment offers a fertile environment from which to collect these types of volunteer data. This point is especially important from an applied standpoint as retention 
can increase efficiency of event-based sporting activities (Kim et al., 2009). In this regard, the Love of Sport motivation appears to be powerful both for sport volun-teers in general (Bang \& Ross, 2009) and, specifically, sport management students (Pierce, Johnson et al., 2014). Career factors are also likely to impact volunteers who want to make a career of working in sport (Pierce, Johnson et al., 2014). Due to prior support for these motivational factors, and the multitude of studies infer-ring the link between satisfaction and retention, the final $R Q$ and hypotheses were created:

RQ3: Does motivation and satisfaction predict retention?

Hypothesis 4: Love of Sport, Career, and Social will predict retention.

Hypothesis 5: Satisfaction will predict retention.

\section{Purpose}

Volunteerism has become an important component of a student's career portfolio as potential employers in the sport industry emphasize the value of volunteer experiences for sport management graduates. Despite this trend, scholars have largely overlooked student volunteers in sport management programs, with the exception of Pierce, Johnson et al. (2014). The current study partially replicated the Pierce, Johnson et al. study by investigating motivation and satisfaction using a similar research design. However, this study expanded the analysis by examining retention differences in addition to motivation and satisfaction. To increase ex-ternal validity that is often questionable when investigating participants from one homogeneous group (i.e., students from one institution or PSO), a greater number of participants from multiple institutions and sport management programs were examined. Therefore, the purpose of this study was to explore characteristics of motivation, satisfaction, and retention among an externally valid representative sample of undergraduate student volunteers from multiple sport management programs. Outcomes may provide academic coordinators and sport organizations with a deeper understanding of volunteer activities, recommendations for an enhanced student volunteer experience, and propositions for evaluating a program's overall volunteer context.

\section{Method}

\section{Participants}

The sample consisted of 322 undergraduate students from five Midwestern institutions in the United States who were sport management majors or pre-majors and had volunteered as a student in the sport management program. By school, $65 \%$ of participants came from two large NCAA DI Football Bowl Subdivision institutions, while $34 \%$ from three smaller (one NCAA DII and two NCAA DIII) institutions. The sociodemographic information revealed a homogeneous sample 
consistent with demographic information previously found in sport management programs (Jones et al., 2008). The mean age was 19.86 ( $S D=$ 1.71), and gender distribution consisted of $73 \%$ male and $26 \%$ female. The majority of the sample was Caucasian (83\%), followed by African American $(9.4 \%)$, and Hispanic $(2.5 \%)$. The sample consisted of freshmen $(33 \%)$, sophomores (27\%), juniors (27.3\%), and seniors (11.8\%).

\section{Instrumentation}

Participants completed a 46-item survey that required ratings of motivation, satisfaction, and intention to continue volunteering. Four demographic items included gender, age, ethnicity, and year in school. All motivation, satisfaction, and retention questions were measured using a 7-point Likert scale. The Volunteer Functions Inventory (VFI) developed by Clary et al. (1998) was used to examine motivation. In both the Clary et al. (1998) and Pierce, Johnson et al. (2014) stud-ies, Cronbach's alpha was above .75 for each motivation factor (Cronbach's alpha levels ranged from .77 to .94 for the current study). Beyond the six motivation factors of the original VFI, a seventh motivation factor of Love of Sport was added based on Bang and Ross (2009) and Pierce, Johnson et al. (2014). Five items from Clary et al. (1998) were used to measure satisfaction. Items were reworded to re-flect the context of this study by adding the words through the sport management undergraduate program. General satisfaction was measured using the mean score from the five items. Lastly, a retention question was developed to measure inten-tion to continue volunteering in the future.

\section{Procedure}

The instrument was distributed in selected sport management undergraduate courses at five different Midwestern institutions. The authors obtained approval from the coordinators of the sport management programs to distribute the instru-ments at the beginning of class. The instrument took approximately 10-15 minutes for students to complete with the researcher available for questions. Prior to administering the survey, it was explained to students that participation was volun-tary. No incentives were utilized and assurances of confidentiality were provided.

\section{Data Analysis}

The demographic variables of gender, age, ethnicity, and year in school were analyzed and reported through descriptive statistics. The seven motivation fac-tors were analyzed via measures of central tendency. A score for each of the seven factors was determined by calculating the mean score of the questions within that particular factor (RQ1). Least Squares multiple regression analysis was used to predict the satisfaction level of participants based on motives (RQ2), as well as retention levels based on motives and satisfaction (RQ3). 


\section{Results}

In terms of RQ1, $\mathrm{H} 1$ was supported, indicating sport management under-graduate students were most motivated to volunteer by Love of Sport $(M=6.47, S D=.84)$ and Career $(M=5.82, S D=.94)$. The lowest motivation factor was Pro-tective $(M=3.70, S D=1.35)$, thus supporting H2. Remaining means and standard deviations for the motivation factors were (in descending order): Understanding $(M=5.47, S D=1)$, Values $(M=5.27, S D=$ $1.01)$, Enhancement $(M=4.63, S D=1.23)$, and Social $(M=4.06, S D=1.17)$.

For $\mathrm{RQ2}$, the seven motivation factors served as predictor variables and the criterion variable was satisfaction. Motivation factors were significantly related to satisfaction, $F(7,314)=45.76, p<.01$. The sample multiple correlation coefficient was .71, indicating approximately $51 \%$ of the variance for satisfaction can be pre-dicted by the seven factors in this study, and confirming $\mathrm{H} 2$. H3 stated that Love of Sport, Career, and Social would best predict satisfaction. Results indicated Career, Understanding, Enhancement, and Social all significantly aid in predicting satisfac-tion (see Table 1). Love of Sport was not a significant predictor of satisfaction, and $\mathrm{H} 3$ was partially supported.

\section{Table 1}

Summary of Least Squares Regression for Variables Predicting Satisfaction

\begin{tabular}{lccccc}
\hline Variables & & Std. Error & Beta & $t$ & Sig \\
\hline Career & .47 & .07 & .35 & 6.44 & $<.01^{* *}$ \\
Social & .24 & .06 & .23 & 4.26 & $<.01^{* *}$ \\
Values & -.12 & .08 & -.09 & -1.55 & .12 \\
Understanding & .30 & .09 & .24 & 3.31 & $<.01^{* *}$ \\
Enhancement & .16 & .08 & .16 & 2.16 & $.03^{*}$ \\
Protective & -.06 & .06 & -.06 & -.89 & .37 \\
Love of Sport & .11 & .07 & .08 & 1.73 & .08 \\
\hline$* p<.05 .{ }^{* *} p<.01$. & & & & &
\end{tabular}

Regarding RQ3, two least squares multiple regression analyses were performed to identify whether motivation and satisfaction predicted retention. Results indi-cated the motivation factors alone accounted for a significant amount of the reten-tion variability, $R^{2}=.45, F(7,314)=37.10, p<.01$, indicating approximately $45 \%$ of the variance for retention can be predicted by motivation variables. $\mathrm{H} 4$ was partially supported as Career and Social significantly aided in predicting reten-tion, while Love of Sport did not (see Table 2). A second analysis was conducted for RQ3 by adding satisfaction as a predictor of retention in combination with the seven motivation factors. The resulting model indicated motivation factors and satisfaction accounted for a significant amount of the retention variability, $R^{2}=.65, F(8,313)=73.12, p<$. 01 . By adding satisfaction to the regression equation, 
approximately $65 \%$ of the variance for retention could be predicted, an increase of $20 \%$ beyond motivation factors alone. Results indicated that for the second model, Career and satisfaction significantly aided in predicting retention (see Table 2). Since satisfaction was a significant predictor of retention, H5 was supported. Fig-ure 1 provides a visual representation of the results in aggregate.

\section{Table 2}

Summary of Least Squares Regression Analyses for Variables Predicting Retention

$\begin{array}{llllll}\text { Variables } & \beta & \text { Std. Error } & \text { Beta } & t & \text { Sig }\end{array}$

Variables Predicting Retention (without satisfaction)

$\begin{array}{llllrc}\text { Career } & .55 & .09 & .37 & 6.45 & <.01^{* *} \\ \text { Social } & .22 & .07 & .19 & 3.33 & <.01^{* *} \\ \text { Values } & .02 & .09 & .01 & .18 & .85 \\ \text { Understanding } & .18 & .11 & .13 & 1.73 & .08 \\ \text { Enhancement } & .17 & .09 & .15 & 1.89 & .06 \\ \text { Protective } & .00 & .07 & .00 & -.01 & .99 \\ \text { Love of Sport } & .01 & .08 & .01 & .14 & .89\end{array}$

Variables Predicting Retention (including satisfaction)

\begin{tabular}{lrrrrc} 
Career & .22 & .07 & .15 & 3.02 & $<.01^{* *}$ \\
Social & .05 & .06 & .04 & .93 & .35 \\
Values & .10 & .07 & .07 & 1.39 & .17 \\
Understanding & -.03 & .09 & -.02 & -.32 & .75 \\
Enhancement & .05 & .07 & .05 & .72 & .47 \\
Protective & .04 & .06 & .04 & .66 & .51 \\
Love of Sport & -.07 & .06 & -.04 & -1.12 & .26 \\
Satisfaction & .70 & .05 & .63 & 13.36 & $<.01^{* *}$ \\
\hline
\end{tabular}

${ }^{*} p<.05 .{ }^{* *} p<.01$. 


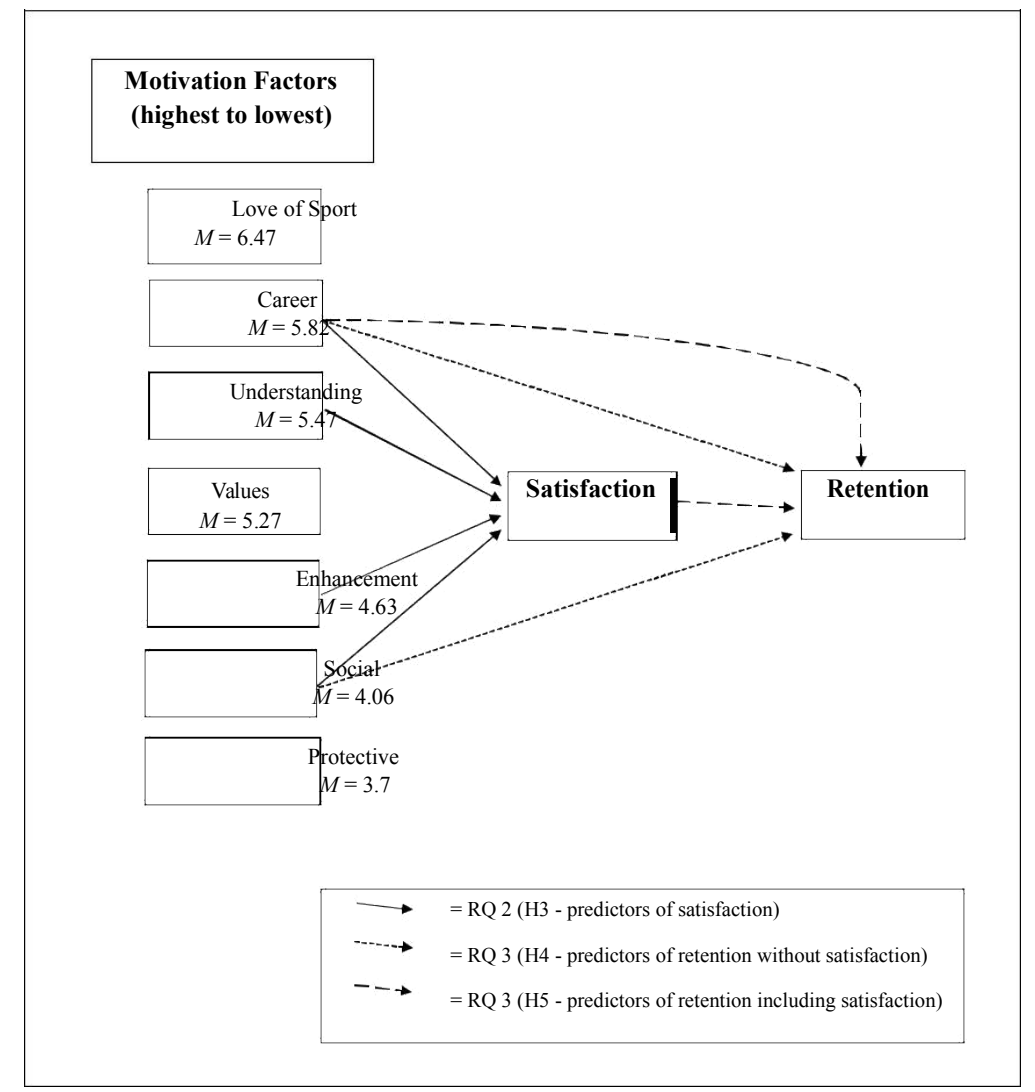

\section{Figure 1. Visual Depiction of Results}

\section{Discussion}

The current study provided empirical evidence linking motivation, satisfaction, and retention of sport management student volunteers. These connections are critical to understanding volunteer characteristics of students with a vested interest in the $\$ 50$ billion sport volunteer industry (Chelladurai, 2014), especially when considering that what motivates sport management students to volunteer is not necessarily what satisfies and retains them. Although results resemble findings by Pierce, Johnson et al. (2014), there are critical differences and extensions that position the current study to fill a void in the volunteer and sport management literature for this unique student population.

For motivation, Love of Sport was the highest ranked motivation factor. Sport management students are often assumed to have a passion for sporting events and activities. In fact, Love of Sport is likely the predominant reason students pursue a sport management major (Mathner \& Martin, 2012; Todd \& Andrew, 2008). Mo- 
tivation results also indicate that individual factors (i.e., Love of Sport) constitute a primary influence of specific volunteer inclusion (Wicker \& Hallmann, 2013). It may first appear surprising that sport management students identified the Social factor as least influential considering literature has illustrated youth and college-aged students volunteer for social reasons (McDougle et al., 2011; Mirsafian \& Mohamadinejad, 2012). However, when one considers the macro context (Wicker

\& Hallmann, 2013) of the academic programs in which sport management stu-dents are enrolled, it is understandable that social motives appear neutralized as a catalyst for initial volunteer interests.

For satisfaction, results were largely dissimilar to the Pierce, Johnson et al. (2014) and Bang and Ross (2009) studies, since Love of Sport did not aid in predicting satisfaction. While Career and Social factors were significant in both the current and Pierce, Johnson et al. (2014) studies, Understanding and Enhancement were also found to be significant predictors of satisfaction in the current study. The Career results are consistent across studies that have indicated college students are motivated by, and satisfied with, volunteer opportunities to enhance their professional careers (Bang \& Ross, 2009; Pierce, Johnson et al., 2014). Although Social was ranked last as a motivation factor, it was a significant predictor of satisfaction both for Pierce, Johnson et al. (2014) and the current study. Thus, sport management students may not specifically volunteer for social reasons, but they do derive satisfaction from Social situations during their volunteer activities.

Discrepancies among satisfaction findings may be linked to dissimilar volunteer contexts, a fact that has been deemed critical to satisfaction (Blackman \& Benson, 2010; Harman \& Doherty, 2014; Vantilborgh et al., 2012). In both the Bang and Ross (2009) and Pierce, Johnson et al. (2014) studies, research samples were one group of homogeneous participants at a single university. Specifically, the Pierce, Johnson et al. study investigated sport management students from a single institution's PSO (i.e., a sport management club). This sample of dedicated students may not have represented the average sport management student. The current study examined students in various sport management classes from mul-tiple universities. Furthermore, institutional differences (e.g., size, athletic pro-gram prestige, volunteer opportunities, curriculum) could have played a role from a contextual standpoint. These potential differences might also explain why Understanding and Enhancement were significant in this study, but not previous ones.

In general, satisfaction results support the individualized and psychological nature of volunteer satisfaction proposed by Herzberg (1966) and explained with-in the psychological contract. For both motivation and satisfaction, the Career factor was significant. This consistency between motivation and satisfaction dem-onstrates the importance that professional development opportunities hold for sport management students. Conversely, other factors that significantly predicted satisfaction (i.e., Social, Understanding, and Enhancement) were not significant predictors of motivation. Therefore, satisfaction is a unique psychometric con-struct largely independent of motivation. Based on outcomes of this study, what motivated sport management students to volunteer was not entirely what contrib-uted to their satisfaction. In spite of the Career factor being consistent for both motivation and satisfaction, findings suggested that social interactions, personal/ professional 
development, and learning experiences also led to students' volunteer satisfaction. Additionally, Love of Sport, which was the most powerful motivating factor, was not a significant predictor of satisfaction-again demonstrating differ-ences between motivation and satisfaction. These findings confirm the conceptual framework by Wicker and Hallmann (2013), whereby contextual differences of institutions may impact volunteer perceptions of students.

To extend the research beyond motivation and satisfaction, this study was the first to examine volunteer retention of sport management students. Initial re-sults (motivation factors only) indicated Social and Career factors were the only significant predictors of retention ( $45 \%$ of retention variance explained). These outcomes support literature linking satisfaction and retention because Social and Career factors together were significant predictors for both satisfaction and re-tention (e.g., Cnaan \& Goldberg-Glen, 1991; Cuskelly et al., 2006; Fairley et al., 2007; Hwang, 2010; Kim et al., 2007, 2009; Strigas \& Jackson, 2003; Taylor et al., 2006). Furthermore, the Social component may be regarded as one of the most prominent considerations to retain individuals within sport contexts (Chelladu-rai \& Ogasawa, 2003; Dixon \& Warner, 2010; Green, 2005). Interestingly, when satisfaction was added to the second regression equation as a predictor variable, Career was the one factor to predict retention in conjunction with satisfaction ( $65 \%$ of variance explained). This $20 \%$ increase in variance is critical to linking satisfaction with retention, and strongly supports the notion that students satisfied with career development opportunities are most likely to continue volunteering. Notably, Love of Sport did not significantly aid in predicting retention despite the established link between Love of Sport and motivation (Bang \& Ross, 2009; Pierce, Johnson et al., 2014). Given that sport is a unique context that draws emotional connections (Warner et al., 2013) this finding is noteworthy. With Career being the lone factor to motivate, satisfy, and retain sport management students, the ful-fillment of the psychological contract appears to be strongly connected to profes-sional development expectations and behaviors of sport volunteer opportunities. This connection is logical considering sport is both a passion and a career path for many sport management students.

\section{Limitations and Future Directions}

A number of limitations are noteworthy. First, this study examined students from five institutions all located in one geographical area (i.e., Midwest U.S.). As a result, the majority of the participants were Caucasian males. While this sample is representative of sport management programs in general, more diverse segments of the population could yield different results. Second, the study did not distin-guish between different types of volunteer experiences. As a result, experiences at 
various levels of sport, activities, and types of sport were treated similarly. Finally, the context of the five academic programs at the institutional level was not taken into consideration relative to findings of the study. In order to comprehensively understand the psychological contract, both individuals and contexts could be considered (Harman \& Doherty, 2014). The nature of sport management academ-ic programs at the macro level (e.g., human resources, finances, planning, network and alumni) could be assessed in relation to the individual (i.e., micro) level of sport management volunteers (e.g., demographic, psychological, economic, and social indicators; Wicker \& Hallmann, 2013).

Future research is encouraged to examine sport management programs from different geographical areas and countries in order to increase the external va-lidity and cross-validate the instrument. Assessment of the person-task, personorganization, and managerial treatment variables (Kim et al., 2007) would cer-tainly provide further insight into elements of the psychological contract for both parties. This analysis of the psychological contract may be particularly important considering the differing event/operational (Kim et al., 200) and executive/coach-ing (Harman \& Doherty, 2014) contexts in which volunteers engage. Researchers could also distinguish between different types of volunteer experiences in terms of opportunities, sport type, and level of study. These experiences could be of greater consideration in combination with a detailed analysis of sociodemographic variables. Satisfaction of the volunteer experience could also be evaluated in more detail, specifically investigating satisfaction for different types of volunteer experiences, duties, or contexts. Despite the popularity of quantitative studies in volun-teer management research, a qualitative study or mixed methods approach with both parties of the psychological contract (i.e., academic programs and students) could add depth to our understanding of motivation, satisfaction, and retention for sport management student volunteers.

\section{Conclusion}

Motivating, satisfying, and retaining volunteers may constitute a challenge for undergraduate sport management programs that often partner with intercolle-giate athletic departments or community sport organizations to provide student volunteers. Results of the current study indicated undergraduate sport manage-ment students were highly motivated to volunteer by career-related benefits and their passion for sport. Program leaders could incorporate these elements into their volunteer recruitment campaigns. Nonetheless, motives that drive students to participate are not necessarily the same factors that contribute most to a satis-fying volunteer experience. Career benefits, social needs, gaining and sharing of knowledge, and personal growth best predicted satisfaction of student volunteers.

Most importantly, this study provided empirical results linking motivation, satisfaction, and retention for sport management students. Considering the dis-tinct role that volunteerism plays in sport management students' search for career 
advantages in a contested and highly competitive industry, this study can inform faculty and industry professionals about recruiting, satisfying, and retaining this important volunteer workforce. Pragmatically, stakeholders should strive to make students satisfied with their volunteer experience by fulfilling the Career, Social, Understanding, and Enhancement motives. For example, satisfaction could be accomplished by providing differing volunteer opportunities or duties as a way to build work-related skills (Career); pairing students with other volunteers or pro-viding team rotations during volunteer tasks (Social); or empowering students by allowing them to have limited leadership roles where they can practice and share their knowledge, which could result in personal growth (Understanding and En-hancement). When satisfied, students are more likely to return. This connection between satisfaction and retention is critical for sport management faculty and partnering organizations to comprehend in their efforts to provide positively re-ciprocal volunteer experiences. Lastly, this study illuminated the importance for academic programs to constantly assess the context and cultural formation of their volunteer offerings both at the institutional and individual level.

\section{References}

Aisbett, L., Randle, E., \& Kappelides, P. (2015). Future volunteer intentions at a major sport event. Annals of Leisure Research, 18(4), 491-510.

Astin, A. (1984). Student involvement: A developmental theory for higher educa-tion. Journal of College Student Personnel, 25, 297-308.

Bang, H., \& Ross, S. D. (2009). Volunteer motivation and satisfaction. Journal of Venue and Event Management, 1, 61-77.

Blackman, D. A., \& Benson, A. M. (2010). The role of the psychological contract in managing research volunteer tourism. Journal of Travel and Tourism Market-ing, 27, 221-235. doi:10.1080/10548401003744669

Bodey, K. (2008). Join the club: Perceived benefits of participating in professional student organizations. Indiana AHPERD Journal, 37, 8-11.

Burns, D., Reid, J., Toncar, M., Fawcett, J., \& Anderson, C. (2006). Motivations to volunteer: The role of altruism. International Review on Public and Nonprofit Marketing, 3, 79-91. doi:10.1007/BF02893621

Chelladurai, P. (2014). Managing organization for sport and physical activity (4th ed.). Scottsdale, AZ: Holcomb Hathaway.

Chelladurai, P., \& Ogasawara, E. (2003). Satisfaction and commitment of Ameri-can and Japanese collegiate coaches. Journal of Sport Management, 17, 62-73.

Clary, E. G., \& Snyder, M. (1999). The motivations to volunteer: Theoretical and practical considerations. Current Directions in Psychological Science, 8, 156- 159. doi:10.1111/1467-8721.00037

Clary, G. E., Snyder, M., Ridge, R. D., Copeland, J., Stukas, A. A., \& Haugen, J. (1998). Understanding and assessing the motivations of volunteers: A func-tional approach. Journal of Personality and Social Psychology, 74, 1516-1530. doi:10.1037/0022-3514.74.6.1516 
Cnaan, R. A., \& Goldberg-Glen, R. (1991). Measuring motivation to volunteer in human services. The Journal of Applied Behavioral Science, 27, 269-284. doi:10.1177/0021886391273003

Currivan, D. (2000). The causal order of job satisfaction and organizational com-mitment in models of employee turnover. Human Resource Management Re-view, 9, 495-524. doi:10.1016/S1053-4822(99)00031-5

Cuskelly, G., Hoye, R., \& Auld, C. (2006). Working with volunteers in sport: Theory and practice. Abington, UK: Routledge.

Dixon, M. A., \& Warner, S. (2010). Employee satisfaction in sport: Development of a multi-dimensional model in coaching. Journal of Sport Management, 24, 139-168.

Fairley, S., Kellett, P., \& Green, C. B. (2007). Volunteering abroad: Motives for travel to volunteer at the Athens Olympic Games. Journal of Sport Manage-ment, 21, 41-57.

Farrell, J. M., Johnston, M. E., \& Twynam, D. (1998). Volunteer motivation, sat-isfaction, and management at an elite sporting competition. Journal of Sport Management, 12, 288-300.

Foster, S., \& Dollar, J. (2010). Experiential learning in sport management: Internships and beyond. Morgantown, WV: Fitness Information Technology.

Giannoulakis, C., Wang, C., \& Gray, D. (2008). Measuring volunteer motivation in mega-sporting events. Event Management, 11, 191-200. doi:10.3727/152599508785899884

Green, C. (2005). Building sport programs to optimize athlete recruitment, reten-tion and transition: Toward a normative theory of sport development. Journal of Sport Management, 19, 233-253.

Han, K. (2007). Motivation and commitment of volunteers in a marathon running event. Electronic Theses, Treatises and Dissertations. Paper 4297. Retrieved from http://diginole.lib.fsu.edu/etd/4297

Harman, A., \& Doherty, A. (2014). The psychological contract of volunteer youth sport coaches. Journal of Sport Management, 28, 687-708.

Herzberg, F. (1966). Work and the nature of man. New York, NY: Cromwell. Hoye, R. (2007). Commitment, involvement and performance of voluntary sport organization board members. European Sport Management Quarterly, 7, 109- 121. doi:10.1080/16184740701270402

Hwang, J. (2010). Does sport really matter to volunteers? Implications from an empirical comparison between sport volunteers and nonsport volunteers. Electronic Theses, Treatises and Dissertations. Paper 3376. Retrieved from http://diginole.lib.fsu.edu/etd/ 3376

Jones, F., Brooks, D., \& Mak, J. (2008). Examining sport management programs in the United States. Sport Management Review, 11, 77-91. doi:10.1016/S1441-3523(08)70104-9

Kim, M., Chelladurai, P., \& Trail, G. T. (2007). A model of volunteer retention in youth sport. Journal of Sport Management, 21, 151-171. 
Kim, M., Trail, G. T., Lim, J., \& Kim, Y. K. (2009). The role of psychological con-tract in intention to continue volunteering. Journal of Sport Management, 23, 549-573.

Mathner, R., \& Martin, C. (2012). Sport management graduate and undergradu-ate students' perceptions of career expectations in sport management. Sport Management Education Journal, 6, 21-31.

McDougle, L., Greenspan, I., \& Handy, F. (2011). Generation green: Understand-ing the motivations and mechanisms influencing young adults' environmen-tal volunteering. International Journal of Nonprofit and Voluntary Sector Mar-keting, 16, 325-341. doi: 10.1002/nvsm.431

Millette, V., \& Gagne, M. (2008). Designing volunteers' tasks to maximize motiva-tion, satisfaction and performance: The impact of job characteristics on vol-unteer engagement. Motivation and Emotion, 32, 11-22. doi:10.1007/s11031-007-9079-4

Mirsafian, H., \& Mohamadinejad, A. (2012). Sport volunteerism: A study on vol-unteering motivations in university students. Journal of Human Sport and Ex-ercise, 7, 73-84. doi:10.4100/jhse.2012.7.Proc1.09

Newman, J. I. (2014). Sport without management. Journal of Sport Management, 28, 603-615.

Nichols, G., \& Ojala, E. (2009). Understanding the management of sports events volunteers through psychological contract theory. Voluntas: International Journal of Voluntary and Nonprofit Organizations, 20, 369387. doi:10.1007/ s11266-009-9097-9

Pavlov, I. P. (1928). Lectures on conditioned reflexes (W. H. Gantt Trans.). London, UK: Allen and Unwin.

Peachey, J. W., Bruening, J., Lyras, A., Cohen, A., \& Cunningham, G. G. (2015). Examining social capital development among volunteers of a multinational sportfor-development event. Journal of Sport Management, 29, 27-41.

Pedersen, P. M., \& Thibault, L. (2014). Managing sport. In P. M. Pedersen \& L. Thibault (Eds.), Contemporary sport management (pp. 431). Champaign, IL: Human Kinetics.

Pierce, D., Johnson, J., Felver, N., \& Wanless, E. (2014). Influence of volunteer motivations on satisfaction for undergraduate sport management students. Global Sport Business Journal, 2, 63-72.

Pierce, D. Wanless, E., \& Johnson, J. (2014). Assessing outcomes of a realistic ma-jor preview in an introductory sport management course. SCHOLE: A Journal of Leisure Studies and Recreation Education, 26, 60-74.

Reeser, J. C., Berg, R. L., Rhea, D., \& Willick, S. (2005). Motivation and satis-faction among polyclinic volunteers at the 2002 Winter Olympic and Para-lympic Games. British Journal of Sports Medicine, 39, e20e20. doi:10.1136/ bjsm.2004.015438 
Strigas, A. D., \& Jackson Jr., E. N. (2003). Motivating volunteers to serve and succeed: Design and results of a pilot study that explores demographics and motivational factors in sport volunteerism. International Sports Journal, 7, 111-123.

Stukas, A. A., Snyder, M., \& Clary, E. G. (2016). Understanding and encourag-ing volunteerism and community involvement. Journal of Social Psychology, 156(3), 243-256.

Taylor, T., Darcy, S., Hoye, R., \& Caskelly, G. (2006). Using psychological contract theory to explore issues in effective volunteer management. European Sport Management Quarterly, 6, 123-147. doi:10.1080/16184740600954122

Todd, S., \& Andrew, D. (2008). An exploratory investigation of sport management students' attraction to sport jobs. International Journal of Sport Management

\& Marketing, 4(4), 323-337. doi:10.1504/IJSMM.2008.022374

Vantilborgh, T., Bidee, J., Pepermans, R., Willems, J., Huybrechtes, G., \& Jegers, M. (2012). Volunteers' psychological contracts: Extending tradi-tional views. Nonprofit and Voluntary Sector Quarterly, 41(6), 1072-1091. doi:10.1177/0899764011427598

Vianen, A. V., Nijstad, B., \& Voskuijl, O. (2008). A person-environment fit ap-proach to volunteerism: Volunteer personality fit and culture fit as predic-tors of affective outcomes. Basic and Applied Social Psychology, 30, 153-166. doi:10.1080/01973530802209194

Wang, P. Z. (2004). Assessing motivations for sports volunteerism. In B. E. Kahn

\& M. F. Luce (Eds.), Advances in Consumer Research Volume 31 (pp. 420-425). Valdosta, GA: Association for Consumer Research.

Warner, S., Tingle, J. K., \& Kellett, P. (2013). Officiating attrition: The experiences of former referees via a sport development lens. Journal of Sport Management, 27, 316-328.

Wicker, P., \& Hallmann, K. (2013). A multi-level framework for investigating the engagement of sport volunteers. European Sport Management Quarterly, 13, 110-139. doi: 10.1080/16184742.2012.744768 


\title{
Motivation, Satisfaction, and Retention of Sport Management Student Volunteers
}

\author{
James E. Johnson, Chrysostomos Giannoulakis, Nathan Felver \\ Lawrence W. Judge, Pierce A. David, and Beau F. Scott
}

\section{Research Problem(s) Addressed}

The purpose of this paper is to examine the motivation, satisfaction, and retention intent of sport management student volunteers. With more than 613 sport management programs in the United States, and more than 8,000 graduates annu-ally, this large group of potential sport volunteers has both a personal and profes-sional interest in sport volunteerism. Much of the volunteer research, however, has neglected to investigate what specifically drives sport management students to volunteer, and ultimately what would keep them coming back. Ignoring sport management student volunteers is particularly problematic considering academic programs routinely include volunteer opportunities as an integral part of the stu-dent experience, and because sport organizations often rely on sport management programs to provide volunteers. Perhaps most importantly, sport organizations likely to acquire these studentvolunteers could improve their recruiting and event organization in a way that would maximize the volunteer experience, and pro-mote volunteer retention.

\section{Issue(s)}

Valued at more than $\$ 50$ billion worldwide, the value of volunteerism within the sport industry is apparent. Volunteers are often a critical component of events who routinely work in areas central to an event's success. For this reason, numer-ous research has focused on studying sport volunteerism, particularly for large scale sporting events such as the Olympics. An often less-studied component of the volunteer industry are college students. Specifically, sport management stu-dents have an inherent interest and unique educational skill set most likely to vol-unteer at sporting events, but have rarely been investigated. In places where sport 
management programs exist, this volunteer workforce can be an important source of incentivized workers with inherent academic and professional reasons to vol-unteer.

Unfortunately, not much is known about the volunteer experiences of sport management students, or if they differ from other college students in their vol-unteer behaviors. For sport management academic programs, this lack of infor-mation is disconcerting because students are regularly encouraged to volunteer through their undergraduate programs and demonstrate a resume/portfolio with discipline-specific experiences. As it stands, faculty/advisors are left largely to edu-cated guesses or general policies that place students in volunteer positions without maximizing benefits for the student and sport organization. Similarly, if sport or-ganizations rely on a volunteer process that does not take into account factors that satisfy and retain these future sport industry professionals, these organizations may be missing an opportunity to capitalize on an important volunteer resource.

The factors identified most relevant in volunteer literature have been motiva-tion and satisfaction. Motivation has often been found to include both external (i.e., environmental) and internal (i.e., psychological) components, and be loosely linked to satisfaction and retention for different volunteer populations. Satisfac-tion has been called the most important component of volunteerism because it directly influences the overall volunteer experience, as well as the intent to re-turn to the volunteer position (i.e., retention). Several studies have isolated these concepts, but few have examined them altogether, or within a sport management student population. By examining these components in aggregate, a more com-prehensive approach to recruitment, programming, and volunteer maintenance can be achieved by academic programs and sport organizations.

\section{Summary}

A total of 322 sport management undergraduate students from five Midwestern institutions were investigated to determine their motivation, satisfaction, and retention intent. Participants mean age was 19.86 years and consisted of mostly males $(73.6 \%)$. These are similar demographic characteristics normally seen in sport management programs. At the beginning of a class session, students completed a 46-item instrument that assessed motivation, satisfaction, and retention intent, as well as demographic information. Each component of the study was analyzed using the six functions from the Volunteer Functions Inventory (VFI), as well as one supplementary component found in additional research (i.e., Love of Sport).

The six factors on the VFI included Values, Understanding, Social, Career, Protective, and Enhancement. The Values factor resembles altruism as it provides an opportunity for volunteers to express their concern for others through helping those that need assistance. The Understanding factor involves the opportunity for volunteers to gain learning experiences while sharing their own knowledge, skills, 
and abilities. The Social factor implies volunteers may be motivated by opportu-nities to work with others and participate in an activity that can enhance social relationships. The Career factor stems from career-related benefits whereby people who volunteer can prepare for a new career or maintain career-relevant skills. The Protective factor focuses on protecting the ego from negative thoughts about oneself, motivating the volunteer by reducing guilt related to being more fortunate than others, or addressing personal issues. The Enhancement factor centers on personal development and obtaining satisfaction related to individual growth and self-esteem. The additional factor, Love of Sport, describes a motivation related to passion associated with a specific sport, or a general sporting environment.

Results supported the three hypotheses of the study and indicated: (1) Volun-teer motivation was greatest for the Love of Sport and Career factors, and lowest for Protective reasons; (2) satisfaction was predicted by Career, Social, Understanding, and Enhancement factors, but not predicted by Love of Sport; and (3) intention to volunteer in the future was best predicted by Career and Social factors, but not Love of Sport. Additionally, a separate analysis revealed that retention intent was predicted most strongly by volunteer satisfaction.

\section{Analysis}

The aforementioned results reveal that what initially motivates sport management students to volunteer is not necessarily what satisfies and retains them. The Love of Sport factor was the most significant for motivation, but not significant at all for satisfaction or retention. Conversely, the Social factor was not a primary volunteer motivation, but was important for satisfaction. Career is the only fac-tor that was consistent across motivation, satisfaction, and retention, suggesting a strong professional orientation for sport management students volunteering at sporting events. The professional development focus was also manifested with the Understanding and Enhancement factors influencing satisfaction, each of which has a knowledge or occupational component at its core.

These findings are critical to consider for both academic programs and sport organizations that frequently supervise and utilize sport management student volunteers. The majority of sport management programs in the U.S. encourage experiential learning and promote volunteer opportunities early in their curriculums so that reasonable volunteer expectations can be fostered. Sport management pro-grams worldwide are progressively incorporating volunteerism into the curricu-lum by offering credit in individual classes, or as a core requirement mandating a set amount of hours to graduate. This gradual establishment of volunteerism as an expected and integral aspect of sport studies requires an organized and sys-tematic approach to recruiting and managing student volunteers. Similarly, sport organizations that utilize sport management student volunteers can take comfort in knowing these students are primarily concerned with professional competence throughout the recruitment and fulfillment of volunteerism. In essence, both aca- 
demic programs and sport organizations can utilize the professional development benefits of volunteer experiences to incentivize students in their volunteer efforts.

\section{Discussion/lmplications}

Studies have repeatedly shown university students are often motivated by professional development and career-centric opportunities. This notion was confirmed in this study, with Love of Sport and Career as significant motivational fac-tors. Thus, in the recruiting phase academic program coordinators or sport orga-nization personnel could emphasize benefits of working in sport that may appeal to Career motives (e.g., resume-building, networking, experiential learning) and Love of Sport (e.g., excitement, action, behind-the-scenes experience). Coordina-tors responsible for securing volunteers could support students in recognizing how volunteer and field experiences can advance their careers, while providing recommendations on volunteer positions related to their specific sport interests. For instance, a student may want to pursue a career in sport operations or game management. In this case, a relevant position close to the field of play could match students' needs and wants. Obviously, students may not always secure their desired position, but matching students with specific sports, positions, and duties would reinforce their Love of Sport. It may also be beneficial to have students rotate and experiment with different volunteer tasks throughout their academic studies so they can formulate a holistic professional development experience. As they get close to graduation students could hone in on more specific volunteer positions, while tailoring their resume for particular internships or occupations.

Satisfaction constitutes a psychometric property that constantly changes based on the nature of the experience. In the current study, satisfaction was enhanced by three conceptually overlapping factors: Career, Understanding, and Enhancement. This indicates that despite students' passion or enthusiasm to experience sport via volunteer opportunities (i.e., motivated by Love of Sport), students' satisfaction was largely driven by the educational and professional component of their vol-unteer endeavors. Therefore, an ongoing assessment of students' satisfaction with their volunteer experiences would provide the knowledge necessary for faculty and sport organizers to position individuals in roles where they can acquire new professional skills based on students' specific desires. Continued feedback of pro-fessional development could come in the form of individual meetings, question-naires, or direct observation. Faculty or sport management professionals could then help guide students to supplementary volunteer experiences and further-ment of skills.

In addition to assessing professional development skills and opportunities, satisfaction for sport management students increases if students are engaged in social experiences during their volunteer roles. Although the Social factor was rat-ed the lowest for motivation, it constitutes a pivotal factor for satisfaction. Often times volunteering in sport events can be a lonely and isolating endeavor where students might be positioned at specific locations or asked to work alone. Paring 
students together, or having task rotations to allow different worker combinations, would increase social interaction during the volunteer activity. Furthermore, pro-moting the social character of volunteerism through acknowledgement (e.g., vol-unteer of the month), social gatherings, and student mentors are possibilities for enhancing social interaction.

As a final consideration, developing a systematic structure for sport management student volunteers is not necessarily a matter of securing additional resources (e.g., hiring a volunteer coordinator etc.). On the contrary, continuous involvement of faculty, sport organizations, community partners, and alumni in this process can only benefit the culture of sport management programs and stu-dent volunteer opportunities. Based on continued evaluation and program exit assessments, supervisors can implement an ongoing plan of volunteerism, mentorship programs for student leaders, and educational workshops. Overall, academic programs should constantly assess both their inner (e.g., number of students and faculty, alumni relations, mission, curriculum etc.) and outer contexts (e.g., geographic location, proximity to sport organizations, community/volunteer partner-ships etc.) when designing and facilitating volunteer opportunities for their stu-dents. Most importantly, a fruitful and satisfying experience for student volunteers can create a legacy of sustained volunteerism for these individuals. Considering that the sport industry relies heavily on services and resources provided by vol-unteers and its viability is dependent upon organized volunteerism, such a legacy facilitated by academic programs and sport organizations is of great importance 
